\title{
How much does it cost?
}

I used to organise dental courses . . . suppose I

had asked dentists to

sign up for the course without having any idea of the cost because I was not certain what the advertising, speaker's fees, hotel charges and so on would

cost me

Mike Grace m.grace.bdj@bda-dentistry.org.uk

\begin{abstract}
he November $200 \mathrm{I}$ issue of Which, the magazine of the Consumers' Association (CA), contains a short story headlined 'Private dentists to get a drilling over prices'. I am not always comfortable about the reports that Which publishes on dentistry, especially when a number of different dentists are criticised for suggesting different treatment options, but this time I feel they have a legitimate point to make.
\end{abstract}

The Consumers' Association has formally asked the Office of Fair Trading (OFT) to investigate private dentistry pricing. This is quite significant because the Consumers' Association has now being given the status of 'supercomplainer' by the government, which means if the CA asks OFT to investigate something then it must do so or provide a satisfactory reason for not doing so. The complaint about private dentistry pricing is the CA's first 'supercomplaint'.

Realistically this is not an unreasonable request. After all, few of us are happy to buy something without knowing the cost first. But I believe that this perceived secrecy over the cost of dentistry makes it seem as if we are ashamed of our own prices. After all, from the public's viewpoint, what other reason could there be for the lack of information over how much it will cost? They are hardly likely to believe that it is due to the fact that we do not know the answer. Yet when I discuss the matter of price lists with dental practices I am constantly informed by dentists and their staff that it is very difficult to know how much private dentistry is going to cost because you do not know how long treatment is going to take or what is wrong until you have carried out a full examination.

I think it is time the dental profession 'got real' about this. After all, dentistry is no different from other businesses and professions, and most of them manage to provide estimates of costs when asked. The plumber never knows exactly what is going to happen when you ask him to fix a problem or install a new bathroom, but he provides you with a price before starting. If something unexpected happens you expect him to inform you and also tell you a new estimate for the changed situation before continuing, not just carry on and give you a much bigger bill at the end. The garage will do the same when it services your car. Why cannot dentists do the same?

Perhaps the situation that the CA is asking for, better clarification on prices before starting dental treatment, would be easier to understand if I took an example from my own past where the dentist was the consumer. Many years ago I used to organise dental courses. Suppose I had asked dentists to sign up for the course without having any idea of the cost (it could be anything in a range from $\mathfrak{E} 100$ to $\mathfrak{1} 1,000$ a day) because I was not certain what the advertising, speaker's fees, hotel charges and so on would cost me. At the end of the course I would then charge a fee because I would then know all my costs. Obviously very few would accept an arrangement like that.

It really is time the dental profession sorted out this particular situation. Although there are early signs we are beginning to change (the BDA's Good Practice Scheme states that the practice makes patients aware of prices), as ever it looks to the outside world like a case of 'too little too late'. The fact that many in the profession are still not providing pricing information easily for private dentistry provides further proof that we are less focused on our patients' requirements and more focused on our own. The CA has felt the need to make this problem its first 'supercomplaint', a reflection of how seriously they are taking the matter. Now is the time for us to remove our heads from the sand and offer to help the CA officially and in as many ways as possible. We know that we do provide value for money in many, many cases. We need to stop looking as if we are afraid to say so. 